\title{
Efficacy of 5-aminolevulinic acid-mediated photodynamic therapy in a mouse model of esophageal cancer
}

\author{
YOSHIHIRO TANAKA, YASUTOSHI MURAYAMA, TATSUYA MATSUMOTO, HIDEMASA KUBO, \\ KYOICHI HARADA, HISATAKA MATSUO, TAKESHI KUBOTA, \\ KAZUMA OKAMOTO and EIGO OTSUJI
}

Division of Digestive Surgery, Department of Surgery, Kyoto Prefectural University of Medicine, Kyoto 6028566, Japan

Received September 12, 2019; Accepted July 2, 2020

DOI: $10.3892 / 01.2020 .11943$

\begin{abstract}
Aminolevulinic acid-mediated photodynamic therapy (ALA-PDT) is a minimally invasive therapeutic modality used in the management of various cancers, but to a lesser extent for esophageal cancer (EC). The current study investigated the antitumor effects of ALA-PDT. Human EC cells were treated with ALA, after which ALA-induced fluorescence was examined under a fluorescence microscope. The cytotoxic effects of ALA-PDT were assessed using three types of LEDs (blue, green and red) in vitro and in vivo. Subcutaneous tumor model mice was constructed with KYSE150 cells. ALA-PDT was performed once a week for 4 weeks and tumor weights were measured. A popliteal lymph node (PLN) metastasis murine model was generated using KYSE150 cells. KYSE150 cells were inoculated into the left footpad of nude mice. ALA-PDT was performed on the footpad once a week for 4 weeks. PLNs were then removed 3 weeks after the last treatment. The lymph nodes were evaluated by hematoxylin and eosin staining. Red fluorescence of protoporphyrin IX (PpIX) was observed in all EC cell lines. ALA-PDT using LEDs exerted significant antitumor effects in vitro and in vivo. The antitumor effects of ALA-PDT with blue LED were the strongest, followed by green and red LEDs. The number of metastasized PLNs was significantly smaller in the ALA-PDT group (0\%) than in the control group (37.5\%). The present results indicated that ALA-PDT is effective for EC.
\end{abstract}

\section{Introduction}

Although advances have been achieved in medical technology in recent years, esophageal cancer (EC) still has a poor prognosis. The five-year survival rate of EC patients undergoing

Correspondence to: Dr Yasutoshi Murayama, Division of Digestive Surgery, Department of Surgery, Kyoto Prefectural University of Medicine, 465 Kajii-cho, Kamigyo-ku, Kyoto 6028566, Japan E-mail: murayama@koto.kpu-m.ac.jp

Key words: 5-aminolevulinic acid, photodynamic therapy, esophageal cancer esophagectomy is only $55.5 \%$ in Japan (1). EC is the 10th leading cause of all cancer deaths in Japan (2). Patients with EC are often diagnosed at an advanced stage with distant metastasis, and, thus, the timing for surgical intervention may be missed. Furthermore, although most patients are eligible for surgery, they often cannot receive chemotherapy or radiotherapy. Therefore, a safer and less invasive treatment is urgently needed.

Photodynamic therapy (PDT) is a minimally invasive therapeutic modality that is used in the management of various cancers, including lung, early gastric, and skin cancers (3-6), as well as pre-malignant diseases (7-10). PDT involves the administration of a non-toxic photosensitizing drug that accumulates in host and tumor cells, and this followed by the illumination of the tumor site with visible light corresponding to an appropriate photosensitizer absorption wavelength (11-13). PDT with Photofrin $^{\circledR}$, Lazerphyrin ${ }^{\circledR}$ and an Excimer-dye laser are the only options commonly available in Japan for the treatment of early gastric cancer and superficial EC. However, the adoption of PDT is decreasing due to the widespread use of endoscopic submucosal dissection (ESD) (14). Furthermore, PDT using Photofrin ${ }^{\circledR}$ and Lazerphyrin ${ }^{\circledR}$ need long shading periods to avoid photosensitivity and, thus, have not been widely adopted.

5-Aminolevulinic acid (ALA) is a second-generation photosensitizer. Protoporphyrin IX (PpIX) is synthesized from 5-ALA in mitochondria (15), and accumulates in several malignant tumors following the administration of ALA (16-18). Once PpIX has accumulated in cells, it absorbs energy from light of an appropriate excitation wavelength in its ground stage, generating excited-state PpIX, which then transfers energy to oxygen. This, in turn, generates cytotoxic reactive oxygen species (ROS), mainly singlet reactive oxygen, which causes cell death $(12,19)$. 5-ALA has the advantage of skin photosensitivity being avoided due to its elimination within $24 \mathrm{~h}(20)$.

ALA therapy is used in dermatology for the treatment of various superficial diseases, such as actinic keratosis, basal cell carcinoma, and Bowen's disease, and good outcomes have been reported (21-23). However, limited information is currently available for gastrointestinal cancer. We previously reported the effects of ALA-PDT on human colorectal cancer cells and gastric cancer cells $(24,25)$. The aim of the present study was to investigate the effects of ALA-PDT on EC cells. 
The efficacy of ALA-PDT in esophageal cancer cell lines was examined at three wavelengths to identify the optimal wavelength. ALA-PDT was performed for esophageal cancer using blue LED, the effectiveness of which remains unclear. The suppressive effects of ALA-PDT on lymph node metastasis were also investigated. To the best of our knowledge, this is the first in vivo study to examine lymph node metastasis of esophageal cancer cells.

\section{Materials and methods}

Cancer cell lines and cultures. We used four types of human EC cell lines. TE5 was purchased from the Cell Resource Center for the Biomedical Research Cell Bank. KYSE70, KYSE150 and KYSE170 cells were purchased from the National Institute of Biomedical Innovation, Health and Nutrition. Cells were grown in RPMI medium with $10 \%$ fetal bovine serum (FBS), $100 \mathrm{U} / \mathrm{ml}$ penicillin, and $100 \mu \mathrm{g} / \mathrm{ml}$ streptomycin at $37^{\circ} \mathrm{C}$ in a water-saturated atmosphere with $5 \% \mathrm{CO}_{2} / 95 \%$ air. TE5 cells were verified by a short tandem repeat analysis and confirmed to be consistent with each other and with the original cell source from the Cell Resource Center for the Biomedical Research Cell Bank. KYSE70, KYSE150 and KYSE170 cells were verified by a short tandem repeat analysis and confirmed to be consistent with the original cell source from the National Institute of Biomedical Innovation, Health and Nutrition.

Animals. Five-week-old female BALB/c nude mice weighing $16-18 \mathrm{~g}$ (18-20 $\mathrm{g}$ by the end of the study) were used in the present study. They were housed in groups in plastic cages with stainless-steel grid tops in an air-conditioned environment with a 12-h light/dark cycle and were provided food and water ad libitum. Animal experiments were conducted in accordance with the institutional guidelines of the Kyoto Prefectural University of Medicine, Kyoto, Japan. The present study was approved by the Ethics Committee of Kyoto Prefectural University of Medicine. The permit number was M28-578. Isoflurane (3\%) was used for induction and $1.5 \%$ isoflurane was used for maintenance of anesthesia in the process of ALA-PDT and measuring small tumors of the mice. During our experiments, all the mice were alive, and almost all of them showed wasting, but they were able to eat and drink normally. All the mice were anesthetized with $3 \%$ isoflurane gas inhalation and sacrificed by cervical dislocation, then the tumors were removed.

Light sources for PDT. Cultured cell plates and inoculated mice were exposed to three types of LED lights (peak wavelength blue, $410 \mathrm{~nm}$; green, $525 \mathrm{~nm}$; red, $635 \mathrm{~nm}$ ). Light intensity was measured using a photo-radiometer.

Fluorescence microscopy analysis. Cells (TE2, TE5, KYSE70, KYSE150) were plated at a density of $1 \times 10^{6}$ cells in glass-bottomed plates. After an incubation for $24 \mathrm{~h}$, cells were treated with $1 \mathrm{mM} 5$-ALA for $3 \mathrm{~h}$, and PpIX fluorescence (excitation, $440 \mathrm{~nm}$; emission, 575-675 nm) was examined under an inverted fluorescence microscope (IX81; Olympus).

PDT in vitro. KYSE170 (5x10 cells $/ 0.1 \mathrm{ml})$, KYSE70, and KYSE150 $\left(2.5 \times 10^{4}\right.$ cells $\left./ 0.1 \mathrm{ml}\right)$ cells were seeded on 96 -well plates and placed in an incubator at $37^{\circ} \mathrm{C}$ for $24 \mathrm{~h}$. Medium was then replaced with that containing $1 \mathrm{mM}$ 5-ALA (Cosmo Bio International) (26). After three hours, 5-ALA-containing medium was replaced with PBS. Cells were irradiated with the three types of LEDs at a light dosage of $3 \mathrm{~J} / \mathrm{cm}^{2}$. PBS was replaced with fresh medium immediately after irradiation. The control group was not administered 5-ALA or exposed to LED irradiation. After $24 \mathrm{~h}$, cell viability was measured using the water-soluble tetrazolium (WST) assay $(24,25)$. Sample absorbance was read on a MAXline microplate reader equipped with a 550-nm filter.

Apoptosis assay. KYSE70, KYSE150 and KYSE170 cells were incubated in a 6-well plate and divided into two groups: a control group and ALA-PDT group. After being cultured for $24 \mathrm{~h}$, cells in the ALA-PDT group were incubated with $1 \mathrm{mM}$ ALA to the final concentration for $3 \mathrm{~h}$, washed with PBS, transferred to fresh medium, and then irradiated with a light dosage of $3 \mathrm{~J} / \mathrm{cm}^{2}$ under blue LED. After ALA-PDT, cells were further cultured for $12 \mathrm{~h}$ and then washed twice with ice-cold PBS. Cells were resuspended in $100 \mu \mathrm{l}$ of binding buffer and stained with $1 \mu \mathrm{l}$ of Annexin V-fluorescein isothiocyanate (Annexin V-FITC) and $5 \mu \mathrm{l}$ of propidium iodide (PI) (Beckman Coulter) at $37^{\circ} \mathrm{C}$ for 15 min in the dark. Cell apoptosis was analyzed by a flow cytometry analysis in a FACScan system (BD Accuri C6; BD Biosciences) (26). At least 30,000 events were collected for each sample.

PDT in vivo (submucosal tumor model). KYSE150 cells $\left(1.0 \times 10^{6}\right)$ were subcutaneously inoculated in $50 \mu \mathrm{l}$ of PBS into the left ankle of nude mice under general anesthesia. Ten days later, the longest diameter of the xenograft tumor was between 3 and $5 \mathrm{~mm}$ (24). Mice were then divided into treatment and control groups. The treatment group was subdivided into the blue-LED, green-LED and red-LED subgroups. The control group and treatment groups comprised 4 or 5 mice each. Nude mice in each treatment group received an intraperitoneal injection of $250 \mathrm{mg} / \mathrm{kg}$ of 5-ALA. Four hours later, mice were irradiated with LED at $30 \mathrm{~J} / \mathrm{cm}^{2}$. The three types of LEDs described above were used in the present study. The control group was not administered ALA or exposed to LED irradiation. ALA-PDT was repeated once a week for 4 weeks. Mice were sacrificed 4 weeks after the initial treatment with isoflurane, and tumors were removed and weighed (27).

PDT in vivo (popliteal lymph node (PLN) metastasis model). KYSE150 cells $\left(1.0 \times 10^{6}\right)$ were inoculated in $100 \mu$ l of PBS into the left footpad of nude mice. After 4 weeks, mice were divided into treatment and control groups (28). The control group and treatment subgroups comprised 8 or 9 mice each. Nude mice in each treatment group received an intraperitoneal injection of $5 \mathrm{mg} /$ body of 5-ALA. After $4 \mathrm{~h}$, the left footpads were irradiated with blue-LED light at a measured rate of $30 \mathrm{~J} / \mathrm{cm}^{2}$. The control group was not administered ALA or exposed to LED irradiation. ALA-PDT was repeated once a week for 4 weeks. Mice were sacrificed with isoflurane 3 weeks after the initial treatment. PLNs were removed and then evaluated by hematoxylin and eosin staining.

Statistical analysis. Differences in weight and size of tumors and cell viability among the groups were analyzed using 
A

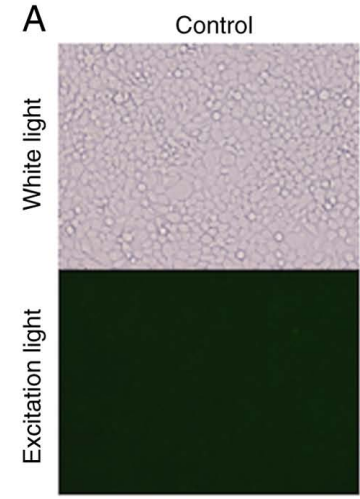

C

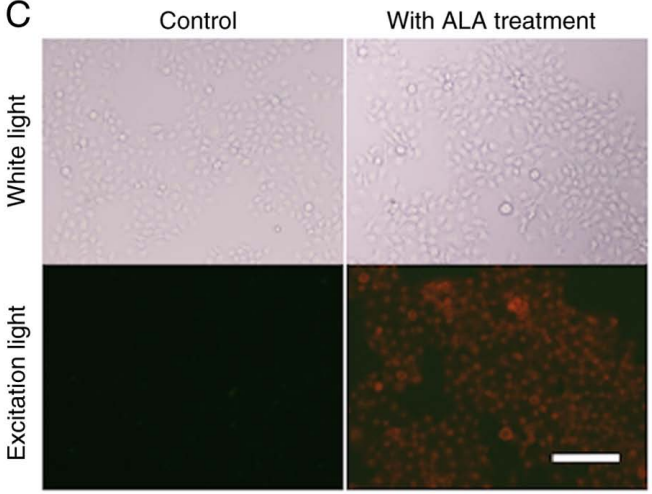

B

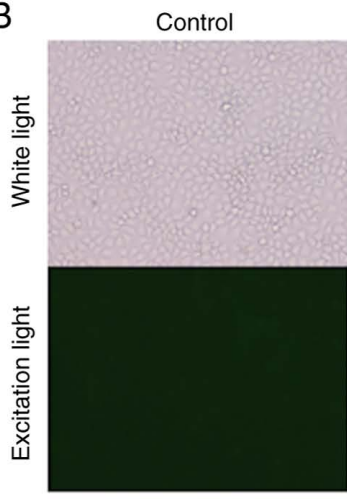

D

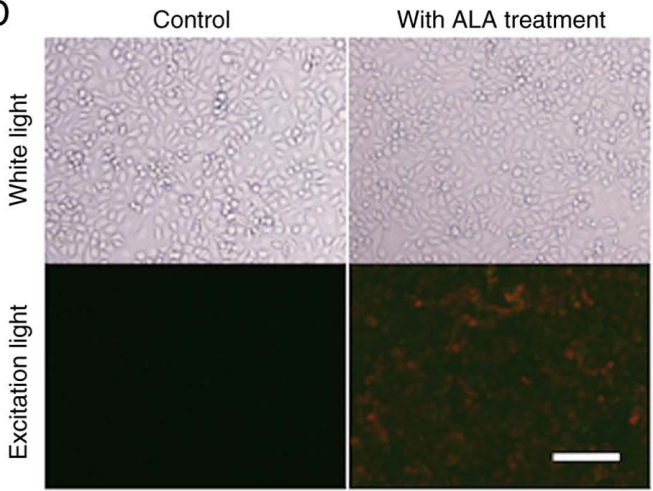

Figure 1. Fluorescence microscopy analysis of esophageal cancer. Images were obtained using (A) TE5, (B) KYSE150, (C) KYSE150 and (D) KYSE170 cells in vitro. Imaging was performed under white and excitation lights (excitation wavelength, $440 \mathrm{~nm}$; emission wavelength, $575-675 \mathrm{~nm}$ ). The red fluorescence of protoporphyrin IX was observed in all esophageal cell lines treated with 5-ALA under excitation light. Scale bar, $100 \mu \mathrm{m}$. ALA, 5-aminolevulinic acid.

ANOVA by using Kruskal-Wallis (non-parametric) H-test. A post hoc Tukey test was subsequently performed. Differences in the number of PLN metastases were analyzed using the Chi-squared test. $\mathrm{P}<0.05$ was considered to be significant.

\section{Results}

Fluorescence microscopy analysis. All fluorescence images were obtained under identical cell conditions, including the photomultiplier voltage, acquisition time, and excitation light intensity. Although there were some variations, the red fluorescence of PpIX was observed in all EC cell lines (TE2, TE5, KYSE70 and KYSE150) treated with 5-ALA (Fig. 1).

PDT in vitro. We used the three types of LEDs (blue, green, and red) that are the most suitable for ALA-PDT in EC. Cell viability was significantly lower in the treatment groups than in the control group (Fig. 2A). Exceptionally, there was no significant difference between the control group and the red-LED group in cell viability of KYSE170. ALA-PDT using blue LED exerted the strongest antitumor effects, followed by that using green and red LEDs $(\mathrm{P}<0.01)$. The same trend was observed for all cell lines investigated. The experiment involved the administration of PDT three times, as previously reported (24). However, this protocol did not result in any significant differences in the sizes of tumors. The administration of PDT four times led to significant differences in LED at each wavelength.

Apoptosis assay. KYSE150 cell apoptosis was assessed by the Annexin V-FITC/PI binding assay followed by flow cytometry.
The apoptosis rate of cells $12 \mathrm{~h}$ after the administration of $1 \mathrm{mM}$ ALA-PDT was $85.8 \%$, which was significantly higher than that in the control group (28.6\%) (Fig. 2B). This result demonstrated that apoptosis was induced by ALA-PDT. Similar results were observed in KYSE70 and KYSE170. However, apoptotic effects were the strongest in KYSE150, suggesting that the induction of apoptosis varies in a cell line-dependent manner.

PDT in vivo (submucosal tumor mouse model): We used three types of LEDs (Fig. 3A). Tumor size and weights at day 29 were significantly lower in the blue-LED groups than in the control group (Fig. 3B-D) $(\mathrm{P}<0.05)$. No significant differences were observed in tumor weights and size between the control group and red-LED group; however, they were slightly lower in the red-LED group. Tumor weights were significantly lower in the blue- and green-LED groups than in the red-LED group $(\mathrm{P}<0.05)$. There was significant difference between green-LED and control group in weight of tumors, but there was no difference in size of tumors at day 29. As in vitro results, In vivo results showed that the effects of PDT were the strongest in the order of blue $>$ green $>$ red LED.

PDT in vivo (PLN model). Metastatic PLNs were significantly smaller in the ALA-PDT group than in the control group $(\mathrm{P}<0.05)$ (Fig. 4A and B). PLNs were removed 3 weeks after the initial treatment (Fig. 4C). In the control group, the formation of metastatic lesions was observed in 3 out of 8 mice (Fig. 4D). Otherwise, no mice had metastatic PLNs in the ALA-PDT group. The number of metastatic PLNs was high in the control group (Fig. 4E). 

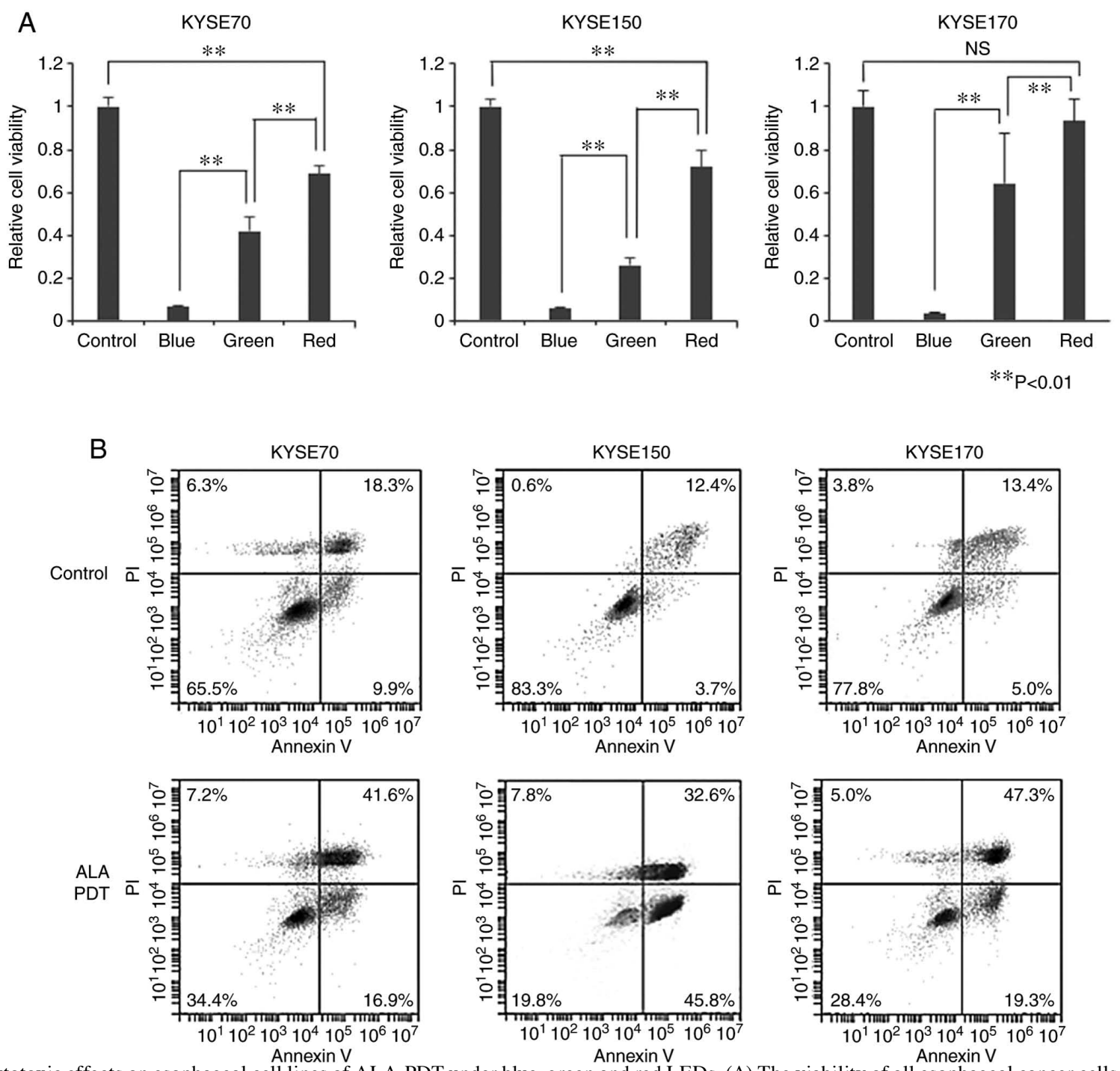

Figure 2. Cytotoxic effects on esophageal cell lines of ALA-PDT under blue, green and red LEDs. (A) The viability of all esophageal cancer cells treated with ALA-PDT using any type of LED was significantly lower than that of control cells. The anticancer effects of ALA-PDT in all cell lines were the strongest under blue LED and the weakest under red LED $(n=4)$. ${ }^{* *} \mathrm{P}<0.01$ as indicated. (B) Apoptosis assay results for control (left) and ALA-PDT (right) treated cells. The apoptosis rate of cells $12 \mathrm{~h}$ after the addition of $1 \mathrm{mM}$ ALA-PDT was $85.8 \%$, which was significantly higher than that of the control group (28.6\%). ALA-PDT, 5-aminolevulinic acid-mediated photodynamic therapy; NS, not significant.

\section{Discussion}

PDT using Photofrin ${ }^{\circledR}$ and an Excimer-dye laser is not widely adopted because it has a long shading time of 6 weeks and a high frequency of hypersensitivity (29). Laserphyrin ${ }^{\circledR}$, which was listed in pharmaceutical affairs in 2015, also has a long shading time of 2 weeks (30). ALA is superior to other photosensitizers because of its rapid metabolism and high selectivity for malignant lesions. The systemic clearance of ALA-induced PpIX within $24 \mathrm{~h}$ prevents prolonged photosensitivity and allows the treatment to be repeated at regular intervals (as frequently as every $48 \mathrm{~h}$ ) without cumulative effects or the risk of damage to normal tissues (20). In the present study, the red fluorescence of PpIX was clearly observed in EC cells in vitro, but not in normal cells. The present results were consistent with previous findings, which showed high selectivity for malignant cells for the accumulation of PpIX with human hepatic cell cancer and colon cancer $(31,32)$. High cancer selectivity may contribute to reducing post-treatment complications.
ALA-PDT is based on ROS being produced following exposure to light and inducing apoptosis in tumor cells (33). With a mitochondrion-associated photosensitizer, photodamage to membrane-bound Bcl-227-29 may be a permissive signal for mitochondrial outer membrane permeabilization and the subsequent release of caspase activators, such as cytochrome $c$. Apoptotic cells promptly release signals required for the clearance of remaining corpses by phagocytic cells, which may minimize damage to normal cells and tissues (34). In the present study, we confirmed that apoptosis was mainly caused by ALA-PDT for human EC cells.

In the present study, we found that the efficiency of ALA-PDT using blue LED was higher than that with red LED. The results obtained are consistent with our previous findings, which showed the efficacy of ALA-PDT using blue LED for human gastric cancer and colon cancer $(24,25)$. Red light is generally used in ALA-PDT (35). The longer the wavelength, the greater the tissue penetration. If the antitumor effects are the same, light with a longer wavelength will be more advantageous for PDT. However, when the wavelength is short, 
A
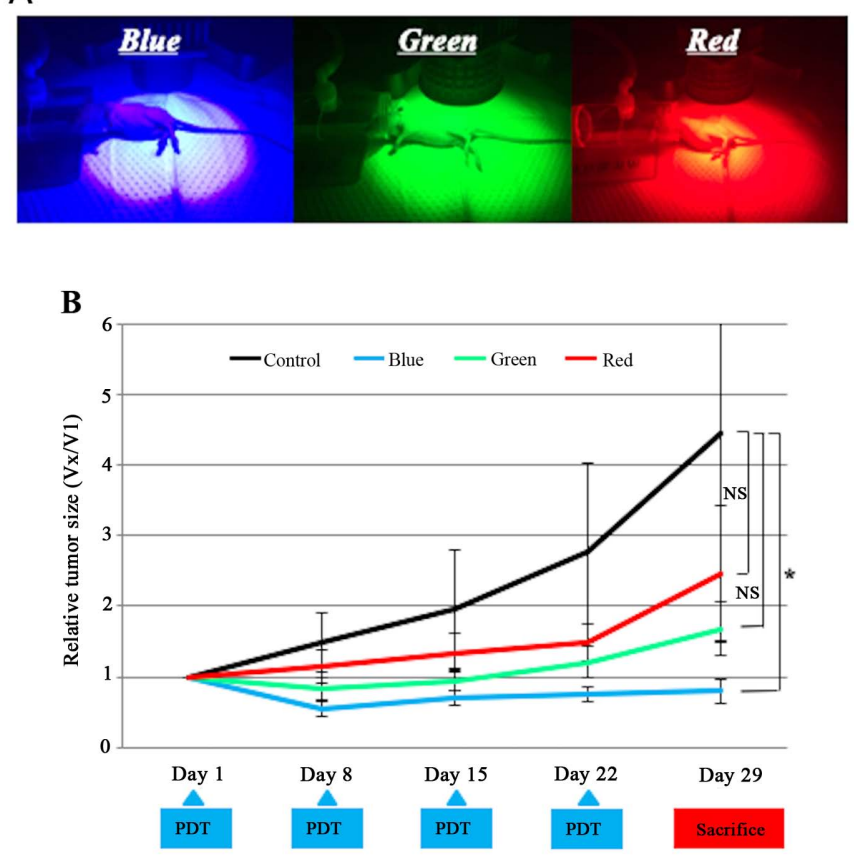

C

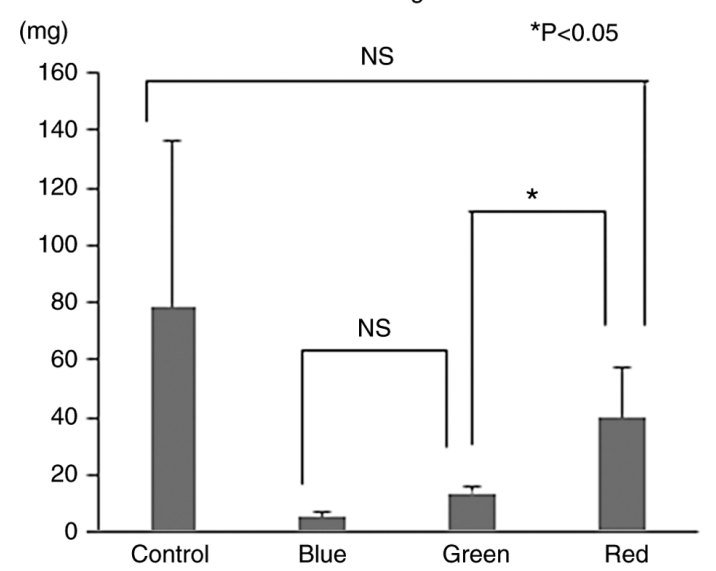

D

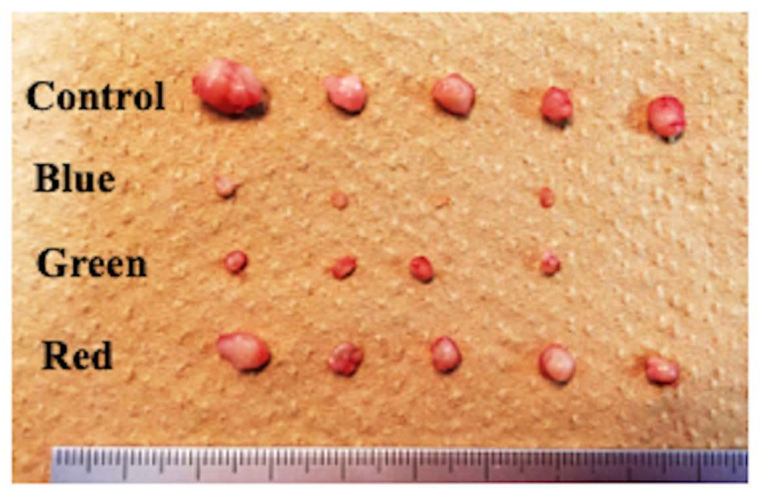

Figure 3. Antitumor effects of ALA-PDT in a mouse model of submucosal esophageal cancer. (A) BALB/c nude mice were irradiated by three types of LEDs (blue, green and red). (B) Treatment course of ALA-PDT using three types of LEDs and the control in BALB/c nude mouse models is demonstrated. ALA-PDT was repeated once a week for 4 weeks. Mice were sacrificed 1 week after the last irradiation and tumors were removed. (C) Comparison of tumor weights. The growth of HT-29 tumors was significantly slower in the treatment groups than in the control group. The antitumor effects of ALA-PDT using blue and green LEDs were stronger than that under red LED. (D) Removed submucosal tumors of each group. ${ }^{*} \mathrm{P}<0.05$ as indicated. ALA-PDT, 5-aminolevulinic acid-mediated photodynamic therapy; NS, not significant. the intensity of light generally becomes stronger. Moreover, absorption by PpIX at $410 \mathrm{~nm}$ is $\sim 30$-fold greater than that at $635 \mathrm{~nm}$. We previously reported that ROS generation was significantly higher in PDT-treated cells with blue LED than with red LED using human gastric cancer cells (25). ROS generated during PDT are responsible for the cytotoxicity of cancer cells. These results suggest that ALA-PDT using blue LED is superior to conventional red LED for the treatment of EC cells. Since the targeted nodules in the present study were only $\sim 3-5 \mathrm{~mm}$ in diameter, tissue penetration by light may not have been as critical. The effects of ALA-PDT may be weakened by the depth of tumors. The depth of the esophageal wall is $\sim 4 \mathrm{~mm}$, while that of early stage EC lesions to the submucosal layer is $\sim 2-3 \mathrm{~mm}$. In the case of PDT for early stage EC, blue LED may be more effective than red LED.

ESD for early EC has recently become more widely adopted because it is a minimally invasive and curative treatment. However, esophageal stenosis sometimes occurs when ESD is performed on lesions of more than $3 / 4$ circumference $(36,37)$. In that case, ESD is not recommended. When we perform ESD, we excise the mucosa to the muscle layer and make a deformation in the esophageal wall. ALA-PDT acts at the mucosa, while not affecting the deeper muscle layers. It may be possible to lower the frequency of stenosis even with circumferential lesions by ALA-PDT. Dunn et al reported the frequency of stenosis with ALA-PDT against high-grade dysplasia arising in Barrett's esophagus, which is a precancerous lesion of EC. ALA-PDT has a more acceptable safety profile than Photofrin-PDT, with a significantly lower incidence of stricture (5.8 vs. $43 \%, \mathrm{P}<0.01)$ (38).

In patients diagnosed with $\mathrm{EC}$, one of the important prognostic indicators for survival after the primary treatment is metastasis to the regional or distal lymph nodes. In the present study, ALA-PDT using blue LED resulted in the partial remission of EC and prevented the occurrence of regional lymph node metastasis. In vivo experiments using PLNs models, tumors in the footpads were only slightly larger in the group with than in that without PLN metastases. The prevention of regional metastasis was confirmed by a histological analysis. None of the mice in the ALA-PDT group had positive nodes, in contrast to $3 / 8$ mice in the control group. The mechanism underlying this additional PDT effect currently remains unclear, but may be due to a direct effect on lymphatic vessels in the illuminated area. Tammela et al previously reported that PDT-treated skin melanoma model mice did not have metastases due to the selective destruction of draining lymphatic vessels (39). We evaluated the efficacy of PDT based on the sizes of the primary lesions (footpads) and incidence of lymph node metastasis. However, the underlying mechanisms were not elucidated. This is a limitation of the present study. Although it was not possible to completely remove the tumor, ALA-PDT showed the potential to inhibit tumor growth and lymph node metastasis similar to ESD. Since ALA-PDT may be performed in a shorter time than ESD, it represents a better alternative for elderly patients.

In summary, for superficial early stage EC with $3 / 4$ circumference or more, ALA-PDT may be an alternative treatment to other PDTs and ESD, particularly in elderly patients.

In conclusion, ALA-PDT using LEDs induced tumor cell death in the EC cell line in vitro and in vivo and prevented 
A
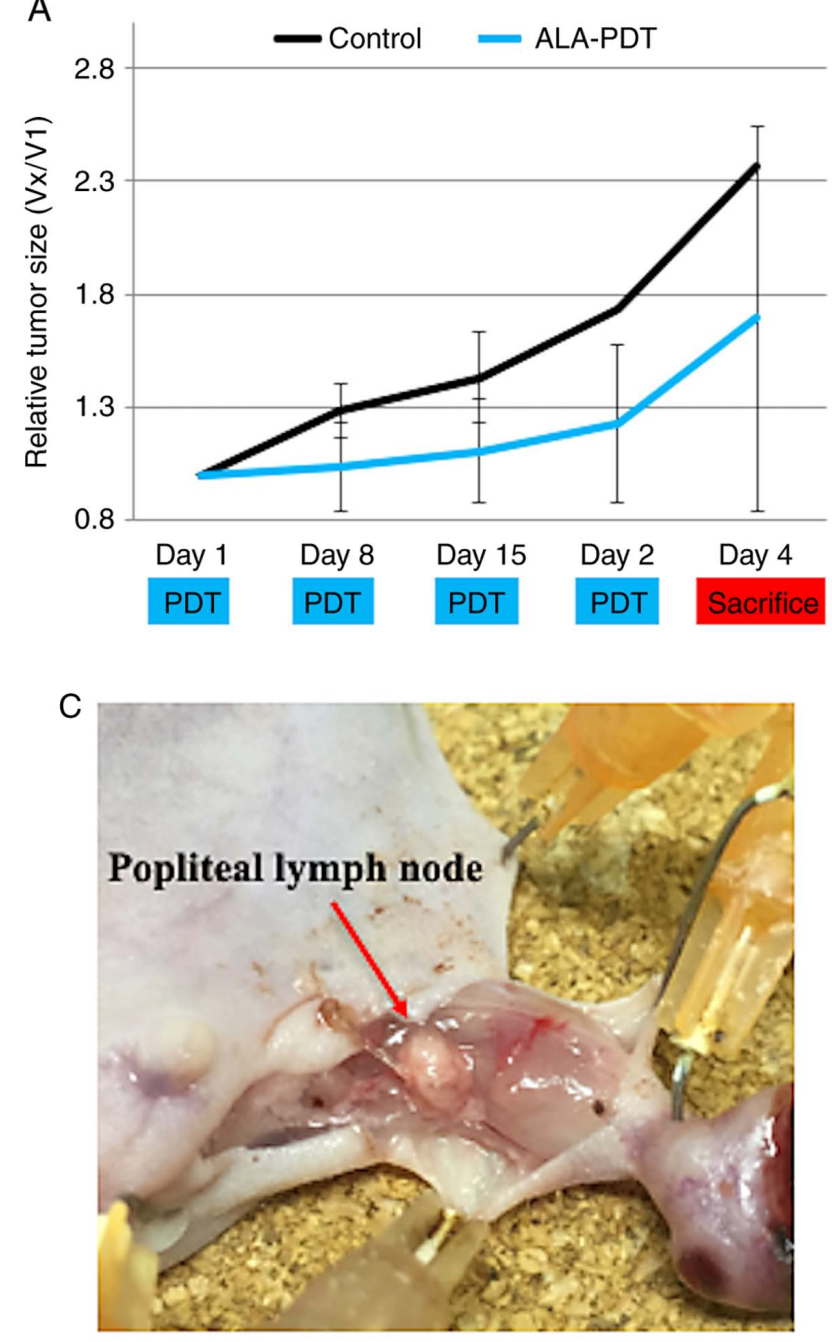

B

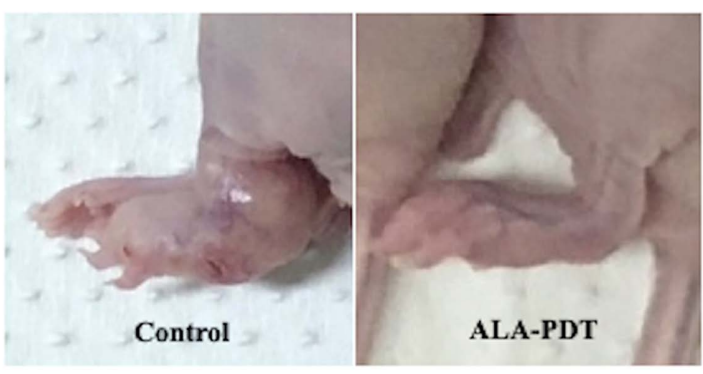

D
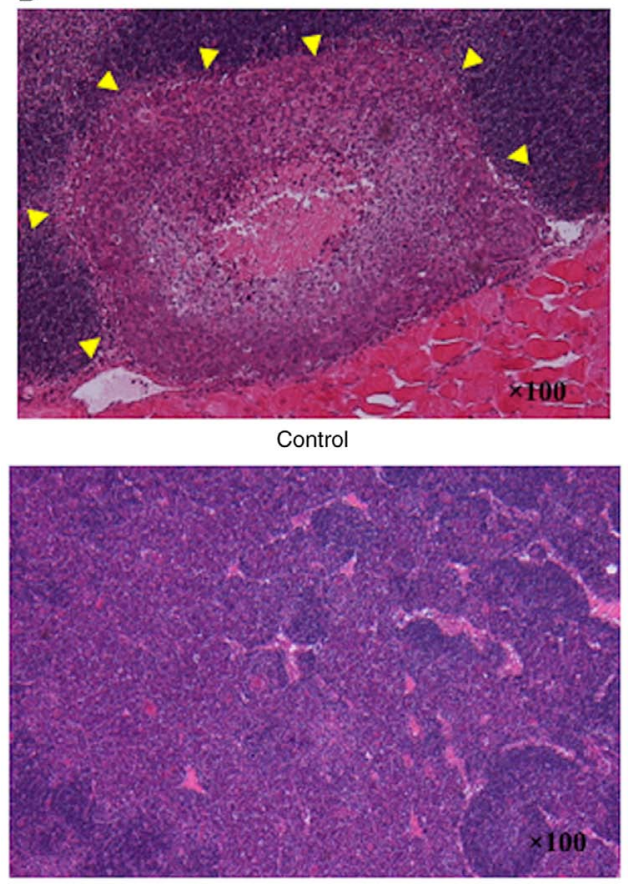

ALA-PDT

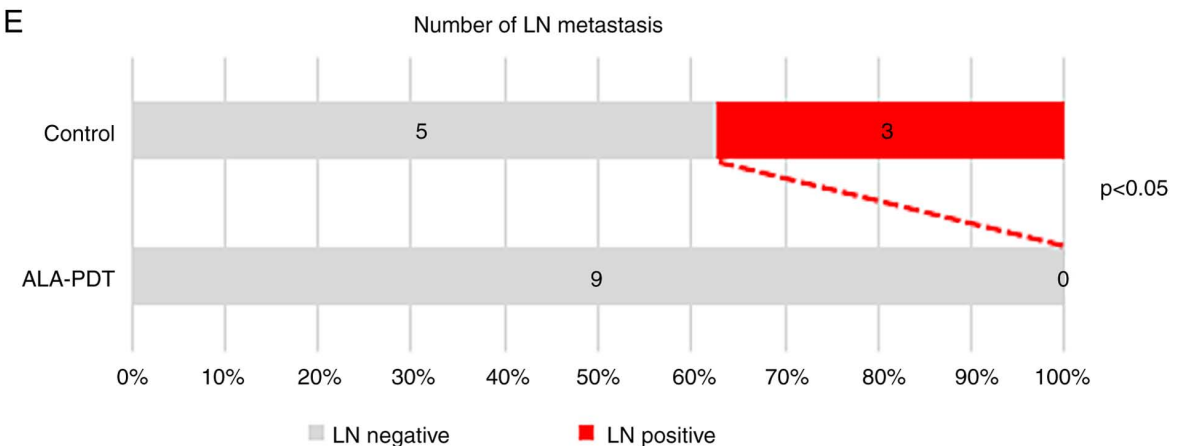

Figure 4. Antitumor effects of ALA-PDT in a mouse model of esophageal cancer demonstrating popliteal lymph node metastasis. (A) Treatment course of ALA-PDT using blue LED and controls in BALB/c nude mouse models. ALA-PDT was repeated once a week for 4 weeks. Footpads treated with ALA-PDT were smaller than those of the control group. The size of the footpad was measured and calculated three-dimensionally (length $\mathrm{x}$ width $\mathrm{x}$ height). The graph demonstrates size changes relative to 1 on day 1. (B) Footpads of each group at sacrifice. (C) PLNs of sacrificed mice (control group). (D) Hematoxylin and eosin staining of PLNs in the control group and ALA-PDT group (magnification, x100). PLNs in the control group had a metastatic region of EC (yellow arrows). (E) Comparison of the number of metastatic PLNs in each group. In the control group, 37.5\% of mice had metastatic PLNs, in contrast to 0\% in the ALA-PDT group. ALA-PDT, 5-aminolevulinic acid-mediated photodynamic therapy; PLN, popliteal lymph node; Vx, measured size at day X; V1, measured size at day 1.

regional lymph node metastasis. ALA-PDT using blue LED exerted stronger effects than conventional red light for small and shallow nodules. The prevention of regional metastasis observed in the present study is of fundamental importance for reducing the negative impact on the quality of life of EC patients and improving overall survival. The present results provide insights into a novel treatment modality for EC.

\section{Acknowledgements}

Not applicable.

\section{Funding}

No funding was received. 


\section{Availability of data and materials}

All data generated or analyzed during this study are included in this published article.

\section{Authors' contributions}

YM designed the current study. YT contributed to data collection and analysis, manuscript writing and editing. TM and HK were involved in project development, data analysis and revision of the manuscript. $\mathrm{KH}$ advised on the use of 5-ALA within the study. HM performed the experiments and analyzed the data. TK, KO and EO analyzed and interpreted the data. All authors read and approved the final manuscript and agree to be accountable for all aspects of the study in ensuring that question related to accuracy or integrity of any part of the work are appropriately investigated and resolved.

\section{Ethics approval and consent to participate}

The present study was approved by the Ethics Committee of Kyoto Prefectural University of Medicine. Animal experimentation within this study was approved by the Institutional Animal Care and Use Committee and performed according to the Animal Experimentation Regulation of Kyoto Prefectural University of Medicine.

\section{Patient consent for publication}

Not applicable.

\section{Competing interests}

The authors declare that they have no competing interests.

\section{References}

1. Tachimori Y, Ozawa S, Numasaki H, Ishihara R, Musubara H, Muro K, Oyama T, Toh Y, Udagawa H9, Uno T; Registration Committee for Esophageal Cancer of the Japan Esophageal Society: Comprehensive Registry of Esophageal Cancer in Japan, 2010. Eshophagus 14: 189-214, 2017.

2. Cancer Registry and Statistics. Cancer Information Service, National Cancer Center, Japan. https://ganjoho.jp/en/public/ statistics/short_pred.html. Accessed October 12, 2018.

3. Dougherty TJ, Kaufman JE, Goldfarb A, Weishaupt KR, Boyle D and Mittleman A: Photoradiation therapy for the treatment of malignant tumors. Cancer Res 38: 2628-2635, 1978.

4. Hayata Y, Kato H, Konaka C, Ono J and Takizawa N: Hematoporphyrin derivative and laser photoradiation in the treatment of lung cancer. Chest 81: 269-277, 1982.

5. Mimura S, Ichii M and Okuda S: Photodynamic Therapy for Early Gastric Cancer Using Excimer Dye Laser. Elsevier Science Publication, Amsterdam, pp272-276, 1992.

6. Lu YG, Wang YY, Yang YD, Zhang XC, Gao Y, Yang Y, Zhang JB and Li GL: Efficacy of topical ALA-PDT combined with excision in the treatment of skin malignant tumor. Photodiagn Photodyn Ther 11: 122-126, 2014.

7. Mlkvy P, Messmann H, Debinski H, Regula J, Conio M, MacRobert A,Spigelman A,Phillips R and BownSG: Photodynamic therapy for polyps in familial adenomatous polyposis - a pilot study. Eur J Cancer 31A: 1160-1165, 1995.

8. Kübler A,Haase T, Rheinwald M, Barth T and Mühling J: Treatment of oral leukoplakia by topical application of 5-aminolevulinic acid. Int J Oral Maxillofac Surg 27: 466-469, 1998.

9. Loh CS, Bliss P, Bown SG and Krasner N: Photodynamic therapy for villous adenomas of the colon and rectum. Endoscopy 26: 243-246, 1994
10. Smolka J, Mateasik A, Cunderlikova B, Sanislo L and Mlkvy P: In vivo fluorescence diagnostics and photodynamic therapy of gastrointestinal superficial polyps with aminolevulinic acid. A clinical and spectroscopic study. Neoplasma 53: 418-423, 2006.

11. Gomer CJ, Rucker N, Ferrario A and Wong S: Properties and applications of photodynamic therapy. Radiat Res 120: 1-18, 1989.

12. Dougherty TJ, Gomer CJ, Henderson BW, Jori G, Kessel D, Korbelik M, Moan J and Peng Q: Photodynamic therapy. J Natl Cancer Inst 90: 889-905, 1998.

13. Dolmans DE, Fukumura D and Jain RK: Photodynamic therapy for cancer. Nat Rev Cancer 3: 380-387, 2003.

14. Yano T, Muto M, Minashi K, Onozawa M, Nihei K, Ishikura S, Kaneko K and Ohtsu A: Long-term results of salvage photodynamic therapy for patients with local failure after chemoradiotherapy for esophageal squamous cell carcinoma. Endoscopy 43: 657-663, 2011.

15. Tsai JC, Wu CL, Chien HF and Chen CT: Reorganization of cytoskeleton induced by 5 -aminolevulinic acid-mediated photodynamic therapy and its correlation with mitochondrial dysfunction. Lasers Surg Med 36: 398-408, 2005.

16. Malik Z and Lugaci H: Destruction of erythroleukaemic cells by photoactivation of endogenous porphyrins. Br J Cancer 56: 589-595, 1987.

17. Kennedy JC, Pottier RH and Pross DC: Photodynamic therapy with endogenous protoporphyrin IX: Basic principles and present clinical experience. J Photochem Photobiol B 6: 143-148, 1990.

18. Peng Q, Moan J, Warloe T, Nesland JM and Rimington C: Distribution and photosensitizing efficiency of porphyrins induced by application of exogenous 5 -aminolevulinic acid in mice bearing mammary carcinoma. Int J Cancer 52: 433-443, 1992.

19. Almeida RD, Manadas BJ, Carvalho AP and Duarte CB: Intracellular signaling mechanisms in photodynamic therapy. Biochim Biophys Acta 1704: 59-86, 2004.

20. Wachowska M, Muchowicz A, Firczuk M, Gabrysiak M, Winiarska M, Wańczyk M, Bojarczuk $\mathrm{K}$ and Golab J: Aminolevulinic acid (ALA) as a prodrug in photodynamic therapy of cancer. Molecules 16: 4140-4164, 2011.

21. Vegter S, and Tolley K: A network meta-analysis of the relative efficacy of treatments for actinic keratosis of the face or scalp in Europe. PLoS One 9: e96829, 2014.

22. Fargnoli MC and Peris K: Photodynamic therapy for basal cell carcinoma. Future Oncol 11: 2991-2996, 2015.

23. Wong TW, Sheu HM, Lee JY and Fletcher RJ: Photodynamic therapy for Bowen's disease (squamous cell carcinoma in situ) of the digit. Dermatol Surg 27: 452-456, 2001.

24. Hatakeyama T, Murayama Y, Komatsu S, Shiozaki A, Kuriu Y, Ikoma H, Nakanishi M, Ichikawa D, Fujiwara H, Okamoto K, et al: Efficacy of 5-aminolevulinic acid-mediated photodynamic therapy using light-emitting diodes in human colon cancer cells. Oncol Rep 29: 911-916, 2013.

25. Hino H, Murayama Y, Nakanishi M, Inoue K, Nakajima M and Otsuji E: 5-Aminolevulinic acid-mediated photodynamic therapy using light-emitting diodes of different wavelengths in a mouse model of peritoneally disseminated gastric cancer. J Surg Res 185: 119-126, 2013.

26. Chen X, Zhao P, Chen F, Li L and Luo R: Effect and mechanism of 5-aminolevulinic acid-mediated photodynamic therapy in esophageal cancer. Lasers Med Sci 26: 69-78, 2011.

27. Wakui M, Yokoyama Y, Wang H, Shigeto T, Futagami M and Mizunuma H: Efficacy of a methyl ester of 5-aminolevulinic acid in photodynamic therapy for ovarian cancers. J Cancer Res Clin Oncol 136: 1143-1150, 2010.

28. Ito T, Shimada Y, Kan T, David S, Cheng Y, Mori Y, Agarwal R, Paun B, Jin Z, Olaru A, et al: Pituitary tumor-transforming 1 increases cell motility and promotes lymph node metastasis in esophageal squamous cell carcinoma. Cancer Res 68: 3214-3224, 2008.

29. Mimura S, Ito Y, Nagayo T, Ichii M, Kato H, Sakai H, Goto K, Noguchi Y, Tanimura H, Nagai Y, et al: Cooperative clinical trial of photodynamic therapy with photofrin II and excimer dye laser for early gastric cancer. Lasers Surg Med 19: 168-172, 1996.

30. Kato H,FurukawaK, Sato M,Okunaka T,Kusunoki Y,Kawahara M, Fukuoka M, Miyazawa T, Yana T, Matsui K, et al: Phase II clinical study of photodynamic therapy using mono-L-aspartyl chlorin e6 and diode laser for early superficial squamous cell carcinoma of the lung. Lung Cancer 42: 103-111, 2003.

31. Murayama Y, Harada Y, Imaizumi K, Dai P, Nakano K, Okamoto K, Otsuji E and Takamatsu T: Precise detection of lymph node metastases in mouse rectal cancer by using 5 -aminolevulinic acid. Int J Cancer 125: 2256-2263, 2009. 
32. Nishimura M, Murayama Y, Harada K, Kamada Y, Morimura R, Ikoma H, Ichikawa D, Fujiwara H, Okamoto K and Otsuji E: Photodynamic diagnosis of hepatocellular carcinoma using 5-aminolevulinic acid. Anticancer Res 36: 4569-4574, 2016.

33. Ishizuka M, Abe F, Sano Y, Takahashi K, Inoue K, Nakajima M, Kohda T, Komatsu N, Ogura S and Tanaka T: Novel development of 5-aminolevurinic acid (ALA) in cancer diagnoses and therapy. Int Immunopharmacol 11: 358-365, 2011.

34. Qiao L, Mei Z, Yang Z, Li X, Cai H and Liu W: ALA-PDT inhibits proliferation and promotes apoptosis of SCC cells through STAT3 signal pathway. Photodiagn Photodyn Ther 14: 66-73, 2016.

35. Peng Q, Warloe T, Berg K, Moan J, Kongshaug M, Giercksky KE and Nesland JM: 5-Aminolevulinic acid-based photodynamic therapy. Clinical research and future challenges. Cancer 79: 2282-2308, 1997.

36. Araki K, Ohno S, Egashira A, Saeki H, Kawaguchi H and Sugimachi K: Pathologic features of superficial esophageal squamous cell carcinoma with lymph node and distal metastasis. Cancer 94: 570-575, 2002.
37. Mizuta H, Nishimori I, Kuratani Y, Higashidani Y, Kohsaki T, Onishi S: Predictive factors for esophageal stenosis after endoscopic submucosal dissection for superficial esophageal cancer. Dis Esophagus 22: 626-631, 2009.

38. Dunn JM,Mackenzie GD,Banks MR,Mosse CA,Haidry R, Green S, Thorpe S, Rodriguez-Justo M, Winstanley A, Novelli MR, et al: A randomised controlled trial of ALA vs. Photofrin photodynamic therapy for high-grade dysplasia arising in Barrett's oesophagus. Lasers Med Sci 28: 707-715, 2013.

39. Tammela T, Saaristo A, Holopainen T, Ylä-Herttuala S, Andersson LC, Virolainen S, Immonen I and Alitalo $\mathrm{K}$ : Photodynamic ablation of lymphatic vessels and intralymphatic cancer cells prevents metastasis. Sci Transl Med 3: 69ra11, 2011.

(i) (9) This work is licensed under a Creative Commons Attribution-NonCommercial-NoDerivatives 4.0 International (CC BY-NC-ND 4.0) License. 